\title{
Nietzschean modes of gender construction in a post-feminist age
}

\author{
by Niklas Serning - Clinical Director, Off The Record, Bristol, UK; and Department \\ of Health \& Social Sciences, University of the West of England, Bristol, UK; \\ and Nina Lyon. PhD candidate, Cardiff University, UK.
}

(Received 12 March 2016; accepted 28 June 2016)

Abstract An arrogance of certainty besets discourses of gender in today's culture, and denigrating as well as overly affirming accounts of masculinity leave the individual man at risk of either self-loathing or self-aggrandising. This paper will look at various lay accounts of masculinity and the dynamics of its construction in opposition to culturally dominant moral codes, and will interrogate the underlying philosophical positions at work through Nietzsche's Genealogy of Morality. In doing so, we propose that it is helpful to see Nietzsche as an early philosopher of difference, and embrace a less fixed approach to ontologies of gender accordingly.

\section{Feminism on masculinity}

It is uncontroversial to regard the majority of socialized human interaction as taking place, or having taken place, within a patriarchal system. The feminist theorist and cultural critic Chris Weedon defines 'patriarchal' as 
power relations in which women's interests are subordinated to the interests as men. These power relations take on many forms, from the sexual division of labour and the social organization of procreation to the internalised norms of femininity by which we live. (Weedon, 1987, pp. 2-3)

Early feminism concerned itself with the struggle for basic protections against destitution and violence for women embedded in patriarchally determined reproductive and domestic roles. By the mid to late nineteenth century, feminist activism was motivated by the extension of the female world beyond domesticity and reproduction, and with the possibility of education and financial autonomy (Sanders, 2001, pp.16-23).

These goals were largely attained in the Western world a century later. Women had the right to vote and work, at least theoretically, in the domain of their choice. Divorce was legal; birth control, though still restricted to married couples, had become available; abortion was, albeit in a limited and patriarchally mediated way, legal in many territories. But disparities between the male and female experience persisted in the home and the workplace. By 1970, the demands of the inaugural Women's Liberation conference at Oxford were for equal pay, equal education and opportunity, 24 hour nurseries, and free contraception and abortion on demand. The embodied experience of biological womanhood demanded external support, in the form of healthcare and childcare, in order to attain some similar status to male-bodied autonomy; the social worlds of work and education and the legislative systems that regulated them continued to regard women's interests as less significant than those of men, if not subservient to them. 
As externally legislated rights for women were won, new feminist behavioural and cultural ideas permeated mainstream discourse. The spectre of the patriarchy had become something to fear, explicitly or implicitly, as a reminder of the importance of these hardwon gains and of the constant ongoing threat to the safety and autonomy of women and their children. UK family law and education policy moved ever further from the 1990s onwards to accommodate the interests of women and girls, and we are now at a point where the previously enshrined patriarchal ownership of children has shifted to a social and often legislative assumption of maternal custody in the case of dispute, and to the point where girls outperform boys at all levels of education.

The much-needed feminist account of patriarchy has gradually become a moral story whose continued assumption of male dominance creates a need for ongoing behavioural controls on masculinity in the interest of women. The necessary (nationally and internationally, relationally and politically) feminist struggle has been misappropriated by a subsection of men and women using it to create moral stories denigrating masculinity, to the detriment of not only masculinity but also the original and valid movement of feminism. To this largely privileged and articulate subsection of men and women, the emphasis is less on concrete needs, and more on correct behaviour. And, we will argue, nowhere is this more patrolled than in the domain of interpersonal relationships, which are themselves subject to profound social change, so that the old, patriarchal rules have all but disappeared, leaving social policing of marriage and partnership in chaotic flux. In a world where the memory of patriarchy, past and present, colours our perception of gendered relations, the onus for correct behaviour - the socially necessitated suppression of desire and will - has 
now started to fall on men rather than the women it had previously fallen upon.

In this paper, we will, with one exception, try to avoid getting caught up in theoretical accounts of gender and how these might be defined. Our interest is with lay accounts of behaviour - of how gender relations are navigated and policed in practice. Our source material is therefore largely online in internet discussion forums where these lay accounts are found. We are interested in reported experiential accounts of relationships and how attitudes to masculinity are expressed in these. We are also interested in the moral frameworks that arise in these accounts, and how they come into being. We offer examples of threads setting out the positions for discussion, but must acknowledge that these have been chosen based on our perception of overall trends rather than any statistical or comprehensive reading of material, which given its quantities would not be possible within our limitations here.

\section{Nietzsche on resentment}

One party, using a position of power, exploits another. The exploited fight for their rightful place in the world, but this fight is usurped by a small, divisive group using it to promote their own moral story. Nietzsche offers us an account that indicates that this is a pattern: slaves revolting against oppression offer an opportunity for the creation of a priesthood which identifies with being oppressed and then leverages that identity to its own end.

For Nietzsche, morality is a system of social policing that arises from the reflexive fear and knowledge of one's own weakness. Nietzsche distinguishes between the 'master' moral 
mode - characterised by strength in loving one's fate, or amor fati, self-sufficiency and the absence of any binding moral codes - and the Sklavenmoral or 'slave morality' based on ressentiment. As in Louise Lumb's contemporary distinction, ressentiment on the part of the slaves stems from a sense of powerlessness and inferiority (Lumb, 2013, p.137).

The beginning of the slaves' revolt in morality occurs when ressentiment itself turns creative and gives birth to values: the ressentiment of those beings who, being denied the proper response of action, compensate for it only with imaginary revenge. Whereas all noble morality grows out of a triumphant saying 'yes' to itself, slave morality says 'no' on principle to everything that is 'outside', 'other', 'non-self': and this 'no' is its creative deed. (Nietzsche, 1887/1994, p.21)

The slave morality, having identified its enemy, then seeks to define the attributes of its enemy in terms of the enemy's intentional moral choices. The enemy behaves in a certain way, and that mode of behaviour runs against our interests, and the way in which it runs against our interests is codified into an account of external moral evil. From the institutional position of a conference fighting for the interests of women, the behaviour of the maledominated world not only runs counter to female interests, and subordinates them to its own, but furthermore appears to carry its own systemic mode of perpetuating those behaviours. It is no great leap to characterise systemic behaviour as ideological; what is reflexively missing is the acceptance that to question ideology is itself an ideological exercise.

But let us return: the problem of the other origin of 'good', of good as thought up by the 
man of ressentiment, demands its solution. There is nothing strange about the fact that lambs bear a grudge towards large birds of prey: but that is no reason to blame the large birds of prey for taking off the little lambs. And if the lambs say to each other, 'These birds of prey are evil; and whoever is least like a bird of prey and most like its opposite, a lamb - is good, isn't he?', then there is no reason to raise objections to this setting-up of an ideal beyond the fact that the birds of prey will view it somewhat derisively, and will perhaps say, 'We don't bear any grudge at all towards these good lambs, in fact we love them, nothing is tastier than a tender lamb.' It is just absurd to ask strength not to express itself as strength, not to be a desire to overthrow, crush, become master, to be a thirst for enemies, resistance and triumph, as it is to ask weakness to express itself as strength. (Nietzsche, 1887/1994, p.27)

In the Nietzschean account, the disempowered resent the powerful for the freedom their power brings. Nietzsche takes no issue with this resentment, seeing it as an entirely rational response to an inequitable world. It is the point at which the disempowered create a legislative moral framework around these notions of good and evil - a legislative framework concocted and enacted by the priesthood - that he sees things turning sour.

Nietzsche's thinking is characterised, on the surface, by a sort of essentialism: there are things or people who are intrinsically strong and noble, the birds of prey, and there are things or people who are intrinsically weak, the baby lambs. In the context of Nietzsche's reflexive and self-contradictory method of discourse, to take this at face value and create fixed categories is mistaken; nonetheless, a useful description of obvious and less obvious power relations can be drawn from it. It is a matter of nature rather than choice for the eagle 
to eat the lamb, just as it is a matter of nature rather than choice for the lamb not to eat the eagle and to be fearful of it. Disparities of power and attributes create inequalities, and inequalities create resentment, and resentment creates a moralising intervention from the bottom of the power disparity to curb the freedoms of the top:

...no wonder, then, if the entrenched, secretly smouldering emotions of revenge and hatred put this belief to their own use and, in fact, do not defend any belief more passionately than that the strong are free to be weak, and the birds of prey are free to be lambs: - in this way, they gain the right to make the birds of prey responsible for being birds of prey... When the oppressed, the downtrodden, the violated say to each other with the vindictive cunning of powerlessness: 'Let us be different from evil people, let us be good! And a good person is anyone who does not rape, does not harm anyone, who does not attack, does not retaliate, who leaves the taking of revenge to God, who keeps hidden as we do, avoids all evil and asks little from life in general, like us who are patient, humble and upright' - this means, if heard coolly and impartially, nothing more than 'We weak people are just weak; it is good to do nothing for which we are not strong enough' - but this grim state of affairs, this cleverness of the lowest rank ... has, thanks to the counterfeiting and self-deception of powerlessness, clothed itself in the finery of self-denying, quiet, patient virtue, as though the weakness of the weak were itself ... a voluntary achievement, something wanted, chosen, a deed, an accomplishment. (Nietzsche, 1887/1994, pp.28-29)

Traditional Greek and Roman notions of virtue saw male virtue in the same light as Nietzsche's nobles: the enactment of the will in line with the shaping forces of nature and the world. Female virtue, as determined by the classical patriarchy, was defined in terms of absence or suppression of desire in favour of familial duty. Correct male sexuality was 
defined by the act of penetration, whatever the gender, age or status of the other party. The classical virtue stories existed to contain female sexuality and will in order to safeguard the transfer of genes and property. These idealised concepts of man as master and woman as willing submissive perpetuated into the gendered imagination as the patriarchy of ancient Greece and the patriarchy of republican and imperial Rome ceded to the patriarchy of the Church.

The irony of the patriarchally propagated notion of power as a masculine virtue is that it is exactly the same gendered notion of power which eventually did for the patriarchy in the post-feminist West. The means by which it happened has a distinctly Nietzschean flavour. What had been context-appropriate female anger at male power became a resentful moral story, and this story maintained the same essentialist and totalising qualities that threatened the individuation of woman and man alike.

\section{Social media on masculinity}

The online world offers a rich seam of lay discourse and debate around gender relations.

From the construction of desirable masculine identities in online dating profiles and forums, to the explicit projects of defining, on the one hand, feminist-acceptable masculinities (e.g. Mumsnet) and post-feminist repatriarchalised masculinities (e.g. 'The Red Pill' (TRP) and 'Men Going Their Own Way' (MGTOW) threads on Reddit), the delineation of masculinity is perpetually revised and contested.

Mumsnet is a popular UK-based parenting forum used predominantly by women with 
children, but also by some men and some childless women. Its threads range from discussion of employment, childcare and parenting to politics, entertainment and relationships. Its breadth of topics and large population of posters bears similarity to the US-based discussion forum Reddit. Reddit's users are predominantly (70\%(Reddit, 2014, February 14a)) male and it seems reasonable to assume that the gender demographics for TRP and MGTOW are near-exclusively male; at the time of writing there are no up-to-date demographic data publicly available for Mumsnet but the website states that a minority of users are male and the means by which male users tend to mention their gender when posting indicates that this difference is noteworthy (Mumsnet, 2015a). Both sites are recognised as being sufficiently influential that high-level politicians seeking election, including the current British Prime Minister David Cameron and US President Barack Obama, have taken part in live chats on Mumsnet (Mumsnet, 2009, November 17) and Reddit (Reddit, 2012, August 29) respectively.

Each site contains a number of forums or subforums with a particular focus on gender and relationships. The ways in which some of these forums differ from one another, and the terms of discourse within them, are instructive as examples of how moral codes are expressed in lay discussion of gendered experience.

The Mumsnet 'Relationships' forum tends to select for questions about marital relationships and dating. One of its characteristics, acknowledged by Mumsnet users in numerous threads debating the validity of its frequent deployment (for example, 2013, September 18), is the acronym LTB (Leave The Bastard), in which an apparently trivial 
initial issue queried by the original poster rapidly snowballs into a diagnosis of domestic abuse sufficiently severe to merit leaving the relationship immediately.

The talk guidelines in Mumsnet's Talk forums and Reddit's MGTOW set the tone for each style of discourse. Mumsnet is orientated towards excising what it deems to be unwarranted conflict from the group discussion, stating that it exists in order 'to make parents' lives easier, so where necessary, we will use our discretion to delete posts (or ban posters) if it seems to us that doing so is in keeping with this aim' (Mumsnet, 2015b).

Under the title 'Post Deletions' Mumsnet sets out a line in which it first states its commitment to freedom of speech before stating that posts 'we consider' to be discriminatory, offensive or 'seriously unpleasant' will be deleted (Mumsnet, 2015b). The use of 'consider' here is itself considered. It creates a legislative system in which the subjective experience of discrimination, offence or unpleasantness validates a post as being discriminatory, defensive, or unpleasant. Subjective affect takes on an ontological status.

As can be seen in the content of many of Mumsnet's relationship threads, this notion of the ontological validity of subjective affect in defining an account of interpersonal events, and of an allied perceived right to be free of negative affect in interpersonal relationships, characterises much of the moral discourse on the site. Before turning to that, though, it is interesting to consider the contrasting tone of discourse set out on Reddit's MGTOW.

MGTOW is upfront about its relationship with feminism: it is a forum in which feminist opinion is not welcome. While Mumsnet sets out at some length what it considers to be 
unreasonable use of language, MGTOW actively avoids any such policing to the extent that those found reporting abuse and posting in support of other posters whom they believe to be unduly criticised will themselves be banned (Reddit, 2015).

MGTOW is concerned, on a superficial level, with privileging expression and avoiding a dynamic of unanimity, and wants a degree of debate, but only within the remit of its own interests. Mumsnet, by contrast, seeks on a superficial level to allow all interests and beliefs, but mitigates against doing so in practice by invoking offence as a category worthy of censorship.

Group practices that encourage self- and peer censorship and mitigate against heterogeneity of opinion banned by MGTOW (Reddit, 2015) are tacitly encouraged by Mumsnet: 'No deliberately inflammatory behaviour' (Mumsnet, 2015b), when subjectively policed, discourages any dissent dissenting sufficient to cause offence.

The overarching moral legislation, therefore, of what can be expressed in both forums is something akin, on MGTOW, to the Nietzschean account of the noble, who enact their will and abhor any attempt to restrict the will of others, even when it is obviously inimical to the interests of external parties, and on Mumsnet to the Nietzschean account of the Sklavenmoral in which Nietzsche situates the Judeao-Christian worldview: there are people out there who abuse or offend us, and we consider ourselves victims of that abuse or offence, and furthermore there are systemic and perhaps ideological reasons for that abuse or offence being caused, so we police ourselves and one another in order to avoid it. 
In order to be a man going his own way, it is necessary to avoid all external shackles on self-expression, one of these being feminism itself. In order for women to communicate with one another, a safe space free from abuse needs to be created, and in doing so various necessary constraints on behaviour are imposed. There is the right to attack and responsibility to allow oneself to be attacked in the neo-masculinist domain of MGTOW and an assumption of vulnerability and the need for protection from attack by proscribing attacking behaviours on Mumsnet.

The Red Pill conception of masculinity sees the body as a site of masculine capital: posters advise one another to 'lift' [weights] in order to build muscle (Reddit, 2015, July 4) and to use their sexuality to have sex with as many concurrent women, described in terminology as 'spinning plates' (Reddit, 2015, September 23), as possible. The act of sexual penetration is alluded to frequently and is both metaphor and metonymy for masculine capital: an Alpha, or high-masculine-capital man, will succeed in attracting one sufficiently to persuade her to 'suck cock' (Reddit, 2014, December 13) and accept anal as well as vaginal penetration (Reddit, 2015, July 26). It is notable that the same sense of masculine capital existed in the Greek and Roman conception of gender: to penetrate, whether woman or man or child, was to enact healthy male sexuality, and to accept penetration was to pervert it and become semivir or half-man. The contemporary terms 'pussy' (Reddit, 2015, May 25) and 'mangina' (Reddit, 2013, December 4) allude metonymically to the same notion of the penetrated half-man - or 'beta' - in TRP dating discourse. 
Penetration is an assertion of will; attaining sex with women exists not in order to establish a relationship, unless she is of sufficient value for reproductive purposes, but as an exercise in self-actualisation. This enactment of the individual will can be bolstered by any means possible, including the sorts of psychological trickery popularised by the allied Pick-Up Artist movement.

The Red Pill paints a picture of contemporary Western thinking about both relationships and individual liberty as characterised by feminised oversocialisation - the term 'gynocracy' is frequently deployed (Reddit, 2014, February 14b). This critique bears remarkable similarities to Theodore Kaczynski's manifesto as the Unabomber, Industrial Society and Its Future. While Kaczynski's description of oversocialisation is embedded in an overall account of the impositions of technology on individual liberty, in which the needs for social cohesion in late industrial society drive an oversocialisation with feminising and leftwing characteristics, his analysis of the present human condition is the same: the individual will is depicted by our culture as aberrant rather than natural, and the biological driving traits that characterise human experience are denied and proscribed in the interests of a peaceful society (Kaczynski, 2010, pp. 44-45).

What Kaczynski is describing here is identical to Nietzsche's account of the JudaeoChristian priesthood in Genealogy of Morality. Nietzsche describes the outcome of the 'methods of the ascetic priests':

the total dampening of the awareness of life, mechanical activity, the small pleasure, above all the pleasure of 'loving one's neighbour', herd-organisation, the awakening of the 
communal feeling of power, the consequence of which is that the individual's dissatisfaction with himself is overridden by his delight at the prosperity of the community ... (Nietzsche, 1887/1994, p.107)

Mumsnet has remarkable political clout in the UK as a parenting forum. Activist threads about particular political or social causes which gather sufficient support from members are taken on as whole-site campaigns. There is a collectivist tone of discourse that characterises not only the activist-dedicated areas of the site but also the discussion of personal experiences and relationships. Posters displaying what is deemed by others to be excessive self-confidence or self-regard in their looks, parenting choices or career are regularly the target of low-level hostility; posters communicating their dissatisfaction with themselves or their situation receive extensive validation and support. There are various emoticons associated with these phenomena: the biscuit emoticon is given as an expression of outrage at what others perceive as a poster's inappropriate sense of entitlement (Mumsnet, 2014, April 2) - or will to power - and the bunch of flowers and glass of wine emoticons generally denote sympathy.

In the relationship threads, where issues around sexual attraction in and outside of marriage and long-term partnership typically come up, there is a marked tendency to defend female interests over male interests, so that if there are two analogous threads in which - for example - a woman complains that her husband wants more sex than she does (Mumsnet, 2010, November 19), and a woman complains that her husband wants less sex than she does (Mumsnet, 2012, April 26), the husband will be perceived as the transgressor of the woman's sexual autonomy in both cases, even if the husband's position in the second 
thread is identical to the wife's in the first. If the husband posts reporting mismatched sex drives in which he wants more sex than his wife, the responses almost uniformly problematize his behaviour (Mumsnet, 2012, February 12). Sexual attraction to a party outside the relationship is, if enacted, considered grounds to end the relationship, but women reporting sexual attraction that has not yet been enacted will generally be asked for contextual information about their marriage and how their husband's behaviour might have eroded desire (Mumsnet, 2015, September 18), while men posting analogous accounts will be accused of seeking to avoid their responsibilities as husbands and fathers and looking for morally inappropriate sex (Mumsnet, 2013, 14 October).

A socially mediated legislative morality that, for reasons of establishing credibility, often calls itself feminist, defines masculinity in these accounts with the same moral fixity as earlier patriarchal structures. Men's sexuality in particular is subordinated to the desires of female sexuality. When a woman instigates sexual contact, it must be met not only with enthusiasm but authenticity: a man who after a long marriage and physical changes on either part no longer feels genuine sexual attraction for his partner is not a 'real man'. When a woman does not want sex and her partner, or any other man, displays sexual interest, if she perceives that interest as oppressive or violating it takes on that status accordingly.

If I feel retrospectively violated by a sexual encounter, I am violated by it. If I feel emotionally abused in my marriage by feeling that my partner's comments are unduly critical and belittling, I am emotionally abused by them. Affect takes on an ontological status: to feel is to be - just as the subjective experience of inappropriate posting is enough 
to ban a post or poster under the Mumsnet Talk guidelines. The tendency of other posters to validate, rather than query, the original poster in the stated spirit of 'making life easier' consolidates this sense of the ontological validity of affect: if everyone agrees that the husband is abusive, it becomes an institutional moral framework, and the husband is abusive.

This, in combination with the stated socialising principles of the Talk guidelines, makes for a crowdsourced morality that accommodates much of both personal experience and social and political activism, and has at least the appearance of validity in numbers: it is hard to argue with hundreds of voices in apparently objective agreement. The combination of a high volume of posts on any particular thread and the dynamic of the agreement bias creates what looks like an external moral fixity. The nature of a fixed moral position is that anything that lies, or is perceived to lie, outside it is then wrong, and a social evil. The power for gender bias in social media to entrench problems in personal relationships rather than seek to overcome them is underpinned by these very different forms of crowdsourced morality.

It is our subjective perception that Mumsnet's Relationship threads, in particular, have lately adopted a more egalitarian tone towards male posters and have encouraged personal responsibility and self-examination. There are also numerous threads on Mumsnet querying the group dynamics and the moral certainties they posit to women seeking advice (Mumsnet, 2012, March 18). 


\begin{abstract}
A Solution
Patriarchal social structures, the reinstatement of which is sought by many of the posters in MGTOW and TRP, depend on the same ancient account of gender essentialism as the prevailing assumption on Mumsnet: men are out for personal gain and women facilitate it. It is a story that rests on the assumption of the male will as the structuring force of human interaction, and of women doing all they can to mediate it rather than enacting their own will for their own purposes.
\end{abstract}

The discussions we have reported on are issues of conflicting desires. Rather than seeing these solely within an overarching moral system - as patriarchy or feminism taking liberties, as the intrinsic evil of the male or female condition - we propose destabilising these moral universes so that desires can be perceived for what they are. In order to unpack conflict we need to unpack its particular motivations, and labelling them as 'The Patriarchy' or 'The Feminazis' (Bates, 2015) is profoundly unhelpful.

The mediator of a Facebook forum aimed at supporting men (https://www.facebook.com/JustSupportingMen) reports the circumstances of his task in moderating comments from a number of opposing gendered ideological positions as follows:

Again, the whole thing is, on both sides, linked to a kind of desperation-forged identity. These people don't know who they are without their ideological identities, so they must protect them at all costs. They don't link truth to experience, but instead a list of rules/concepts (patriarchy, wilfulness, victimhood) upon which their identity sits. 
Attack any of them and they freak out, because who are they if one of these ideas is wrong, or even just not universally true? (John McGuirk, personal communication, 2015, September 3)

Behind the apparently extreme edifice of Nietzsche's assertions about morality, a mass of internal contradiction indicates that no single assertion should be taken at face value. Nietzsche can be seen as forming part of an early canon of philosophy of difference opposing the pursuit of fixity, moral or otherwise (Lawson, 1985, pp.32-55). If we unpack what we mean exactly by gender, a similar set of contradictions often emerges too.

Contemporary post-structuralist feminist critics like Gayatri Spivak have challenged binaristic notions of woman as not-man, and in particular the idea that language and rhetoric have constructed an account of femininity - and indeed masculinity - that is taken to be an objective truth. Spivak, writing on the subaltern, takes a line whose intended outcome might be similar to Nietzsche's, if more moderately expressed.

The position that only the subaltern can know the subaltern, only women can know women and so on, cannot be held as a theoretical presupposition either, for it predicates the possibility of knowledge on identity. Whatever the political necessity for holding the position, and whatever the advisability for attempting to 'identify' (with) the other as subject in order to know her, knowledge is made possible and sustained by irreducible difference, not identity. (Spivak, 1987, p.253)

We propose that taking a philosophy of difference in this mode is a more constructive 
strategy when seeking accounts of gender and desire. Without it, one moral certainty based on the fear of an imagined other only ever crumbles to be replaced by another, equally divisive moral certainty, and the nature of moral certainties is that only the most strident and certain voices can be heard. 


\section{References}

Bates, L. (2015). 10 ways you can tell if you're a 'feminazi'. Guardian online. 2015, September 11. Retrieved from http://www.theguardian.com/commentisfree/2015/sep/11/how-to-be-a-feminazi-feminist

Kaczynski, T. (2010). 'Industrial Society and Its Future', Technological Slavery: The collected writings of Theodore J. Kaczynski. Port Townsend: Feral House Press.

Lawson, H. (1985). Reflexivity. London: Hutchinson.

Lumb, L. (2013) 'Ressentiment: The Air We Breathe And The Way We Breathe'. Existential Analysis, vol.24.

Mumsnet. (2009, November 17). Live webchat with David Cameron - this Thursday 19th, $1.45 \mathrm{pm}$. Retrieved from http://www.mumsnet.com/Talk/mumsnet_live_events/862722Live-webchat-with-David-Cameron-this-Thursday-19th-1-45/AllOnOnePage

Mumsnet. (2010, November 19). I refused to have sex with dh because I just couldnt be arsed. Retrieved from http://www.mumsnet.com/Talk/relationships/1087062-I-refusedto-have-sex-with-dh-because-I-just-couldnt-be-arsed 
Mumsnet. (2012, February 12). Mismatched sex drive. Retrieved from http://www.mumsnet.com/Talk/relationships/1405321-Mismatched-sex-drive Mumsnet. (2012, March 18). To be fed up with the pack mentality. Retrieved from http://www.mumsnet.com/Talk/am_i_being_unreasonable/1431587-To-be-fed-up-withthe-pack-mentality

Mumsnet. (2012, April 26). DH has no sex drive whatsoever. Retrieved from http://www.mumsnet.com/Talk/relationships/1459511-DH-has-no-sex-drive-whatsoever Mumsnet. (2013, September 18). Should strangers really be advising women to leave their husbands? Retrieved from http://www.mumsnet.com/Talk/relationships/1856177Should-strangers-really-be-advising-women-to-leave-their-husbands Mumsnet. (2013, 14 October). Am I about to throw everything away? Retrieved from http://www.mumsnet.com/Talk/relationships/1881171-Am-I-about-to-throw-everythingaway

Mumsnet. (2014, April 2). Darling MNHQ, please, please, please could you arrange for the Biscuit Emoticon to fucking do one? Retrieved from http://www.mumsnet.com/Talk/site_stuff/a2043422-Darling-MNHQ-please-pleaseplease-could-you-arrange-for-the-Biscuit-Emoticon-to-fucking-do-one 
Mumsnet. (2015, September 18). Sex-less marriage - want to kiss someone else.

Retrieved from http://www.mumsnet.com/Talk/relationships/2470471-Sex-less-marriagewant-to-kiss-someone-else?pg=2

Mumsnet. (2015a). I'm not a mum - can I still join Mumsnet? Retrieved from http://www.mumsnet.com/info/faqs

Mumsnet. (2015b). Mumsnet's Talk Guidelines. Retrieved from http://www.mumsnet.com/info/netiquette

Nietzsche, F. (1887/1994). On the Genealogy of Morality. (trans. Carol Diethe, ed. Keith Ansell-Pearson). Cambridge: Cambridge University Press.

Reddit. (2012, August 29). I am Barack Obama, President of the United States - AMA. Retrieved from https://www.reddit.com/comments/z1c9z/i_am_barack_obama_president_of_the_united_ states/

Reddit. (2013, December 4). The Rise Of The Mangina. Chivalry is dead and it's time to accept. Retrieved from https://www.reddit.com/r/TheRedPill/comments/1s42vi/the_rise_of_the_mangina_chivalr y_is_dead_and_its/?) 
Reddit. (2014, February 14a). Subreddit Gender Ratios [OC]. Retrieved from https://www.reddit.com/r/dataisbeautiful/comments/1wtnkd/subreddit_gender_ratios_oc/

Reddit. (2014, February 14b). Red Pill: The End Game. Retrieved from https://www.reddit.com/r/TheRedPill/comments/1z7xw2/red_pill_the_end_game/?

Reddit. (2014, December 13). How I landed a foursome on my last night before leaving for break using TRP. Retrieved from https://www.reddit.com/r/TheRedPill/comments/2p7ay3/how_i_landed_a_foursome_on_ my_last_night_before/?

Reddit. (2015, May 25). The new male only sex ed program that is turning young boys... into beta pussies. Retrieved from https://www.reddit.com/r/TheRedPill/comments/3793h3/the_new_male_only_sex_ed_pr ogram_that_is_turning/?

Reddit. (2015, July 4). A Quick Testimony of Why The First TRP Advice is Lift. Retrieved from https://www.reddit.com/r/TheRedPill/comments/3c4ofq/a_quick_testimony_of_why_the _first_trp_advice_is/?

Reddit. (2015, July 26). Girls want to be degraded and dominated by a high-value man. Retrieved from 
https://www.reddit.com/r/TheRedPill/comments/3eq8j8/girls_want_to_be_degraded_and _dominated_by_a/?

Reddit. (2015, September 11). Roles, respect and responsibility acceptance as an alpha trait. Retrieved from https://www.reddit.com/r/TheRedPill/comments/3k8uxw/roles_respect_and_responsibilit y_acceptance_as_an/

Reddit. (2015, September 23). What Is And Is Not Plate Spinning. Retrieved from https://www.reddit.com/r/TheRedPill/comments/3m45p7/what_is_and_is_not_plate_spin ning/

Reddit. (2015). MGTOW - Rules. Retrieved from https://www.reddit.com/r/MGTOW

Ruden, S. (2001). 'Ancient Views on Sexuality', in Petronius, Satyricon (trans. and ed. Sarah Ruden). Indianapolis: Hackett.

Sanders, V. (2001) 'First Wave Feminism', in Sarah Gamble (ed.), The Routledge Companion to Feminism and Post-Feminism. London: Routledge.

Spivak, G. (1987). 'A Literary Representation of the Subaltern', In Other Words: Essays in Cultural Politics. London: Methuen. 
Weedon, C. (1987). Feminist Practice and Poststructuralist Theory. Oxford: Blackwell. 